\title{
Performance and Surface Integrity of Wire Electrical Discharge Machining of Thin Ti6al4v Plate Using Coated and Uncoated Wires
}

\author{
Fred Lacerda Amorim ${ }^{a} \mathbb{D}$, Ricardo Diego Torres ${ }^{a}$, Carlos Augusto Henning Laurindo ${ }^{a}$, Luca Watanabe Reolon ${ }^{a}$ \\ a Programa de Pós-Graduação em Engenharia Mecânica - PPGEM, Pontifícia Universidade Católica \\ do Paraná - PUCPR, Av. Imaculada Conceição, 1155, Prado Velho, 80.215 901, Curitiba, PR, Brasil
}

Received: February 11, 2019; Accepted: April 29, 2019

\begin{abstract}
Wire Electrical Discharge Machining (WEDM) is one of the most important production technologies to manufacture very accurate small components and tools on any electrical conductive material. Titanium and its alloys have been widely used in automobile and aerospace industry as well as in medical engineering field. Small components and tools with complex geometrical shapes are difficult to be produced on titanium alloys by both conventional and nonconventional machining technologies. In this work an experimental investigation on the influences of wire electrode type and electrical variables when WEDM a thin plate of Ti6A14V alloy has been carried out. Uncoated brass wire and copper wire with a diffused zinc coating were used for the experiments. Interval time, wire run-off speed, discharge duration and dielectric inlet pressure were evaluated in order to achieve adequate process parameter settings. Characteristics of surface integrity were also investigated. The best technological results for all tested WEDM parameters were attained for copper wire with a diffused zinc coating. The recast layer of the samples WEDMachined with the copper wire presented a smaller thickness and more compact than that obtained with uncoated brass wire. For WEDM with both types of wire, the existence of thermal cracks was observed.
\end{abstract}

Keywords: wire electrical discharge machining (WEDM), Ti6Al4V alloy, process performance, surface integrity.

\section{Introduction}

Titanium and its alloys have low specific density and mechanical strength much similar to that of steel. In fact, the ratio between strength and density of titanium alloys is the highest among the metallic materials. This material also has significant characteristics such as good heat and corrosion resistances. For such reasons, for many years titanium and its alloys have been widely used in aerospace and automobile industries. It has also important applications in medical engineering field, because of its high biocompatibility. Examples include joint replacement parts for hip, knee, spine, dental implants and surgical instruments ${ }^{1}$.

However, according to Wansheng et al. ${ }^{2}$, manufacturing small geometrical complex shapes onto titanium-based alloys are very difficult by the majority of conventional machining processes (e.g. milling, drilling, and turning). The stiffness of the cutting tool, removal of chips and tool cooling are common problems in conventional machining. It is due to titanium alloys' low thermal conductivity and toughness, as pointed out by Znidarsic \& Junkar ${ }^{3}$. Also, notching at the tool nose, flank and crater wear, chipping and catastrophic cutting tool failure are some of the common failure modes occurring when machining titanium ${ }^{4}$.

Recent years have seen that miniaturization has become an increasing demand by a wide variety of industrial products ${ }^{5}$.

*e-mail: fred.amorim@pucpr.br.
As reported by Masuzawa ${ }^{6}$ miniaturized components are a trend in many daily applications such as cameras, watches, audio and video equipment etc. In the case of aerospace engineering very small components machined on special alloys, such as titanium, is a real necessity. Small products can contain more functions in a limited space. Equipment used in medicine such as surgical instruments is another example of miniaturization trend, as well as titanium alloys replacement parts for the human body. However, high precision manufacturing processes are required to accomplish these sophisticated tasks, e.g. components smaller than 0.5 $\mathrm{mm}$ in size.

Masuzawa ${ }^{7}$ also states that there are many technologies that can be used to produce small components, because the necessary conditions to machine such parts are very small material removal rate and high precision. At this point can be included electrical discharge machining (EDM), ultrasonic machining (USM), laser beam machining (LBM), ion beam machining (IBM), electron beam machining (EBM) and electrochemical machining (ECM). Each one of those manufacturing processes has its own technical and cost restrictions.

The electrical discharge machining (EDM) is a nonconventional machining process that uses the conversion of electrical energy into thermal energy to remove material from the workpiece. Consequently, the EDM efficiency depends essentially on the thermophysical properties of the wire electrode and the workpiece to be machined ${ }^{8}$. 
Hasçhk and Çaydas ${ }^{9}$ emphasizes that there is a relative deficiency of research in EDM of titanium alloys concerning parameter settings optimization for different electrode materials as well as studies on aspects of surface integrity characteristics.

Klocke et $a l .{ }^{10}$ also remarked that some WEDM technological constraints are mainly related to the following essential topics: working accuracy, wire electrode material, type of dielectric and its properties and WEDM parameter settings concerning rough and finish cuts for each different workpiece material.

Considering the aforementioned arguments this work investigates the influences of wire electrode type and electrical variables when WEDM a thin plate of Ti6Al4V alloy. Uncoated brass wire and copper wire with a diffused zinc coating were used for the machining experiments. Characteristics of Ti6Al4V workpieces surface integrity such as recast layer, pores, and microcraks were also investigated.

\section{Experimental Procedures}

The experimental tests were carried out on a Charmilles Robofil 290 CNC WEDM machine tool equipped with an isoenergetic generator, where is possible to set the discharge energy $\left(\mathrm{W}_{\mathrm{e}}=\mathrm{u}_{\mathrm{e}} \cdot \mathrm{i}_{\mathrm{e}} \mathrm{t}_{\mathrm{e}}[\mathrm{J}]\right)$. Uncoated brass wire $(\mathrm{CuZn}$ 63/37\%, $500 \mathrm{~N} / \mathrm{mm}^{2}$ tensile, $20 \%$ elongation) and copper wire with a diffused zinc coating ( $\mathrm{CuZn}$ coating, $900 \mathrm{~N} / \mathrm{mm}^{2}$ tensile, $1.5 \%$ elongation) electrodes with $0.25 \mathrm{~mm}$ diameter, manufactured by Charmilles, were used. The wires were set at negative polarity, using low discharge duration, to provide prominent action of electrons over the workpiece surface and less ions effect on the wire surface, which in its turn could cause the wire breakage. The following variables were investigated:

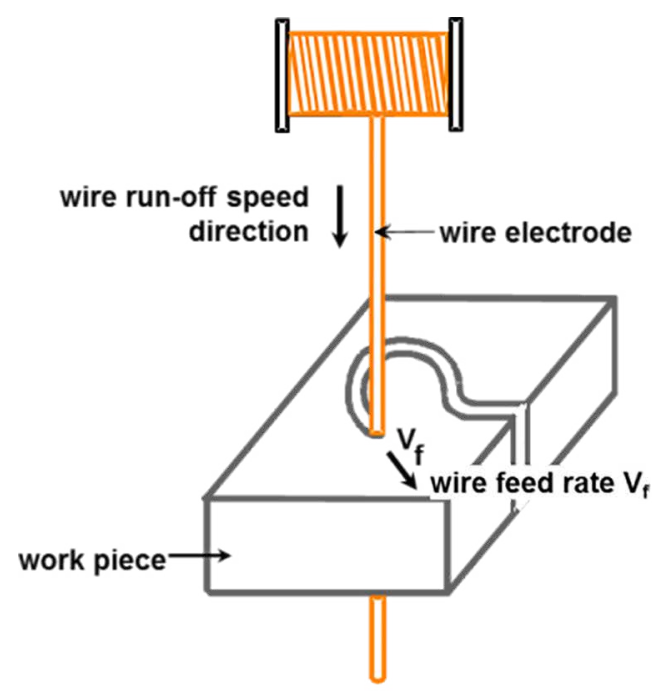

(A)
- Interval time $\mathrm{t}_{\mathrm{o}}[\mu \mathrm{s}]$ : the time between two successive voltage pulses;

- Wire run-off speed $\mathrm{W}_{\mathrm{s}}[\mathrm{m} / \mathrm{min}]$ : This represents the velocity of the wire in its longitudinal direction. The continued wire run-off motion is necessary to compensate the erosion wear.

- Discharge duration $t_{e}[\mu \mathrm{s}]$ : the period of time of the current flow through the working gap after breakdown.

- Dielectric inlet pressure $\mathrm{p}_{\text {in }}$ [bar]: the pressure of the dielectric fluid pumped into the working gap through the upper and lower nozzles of the machine heads.

Figure 1 depicts the routes of a wire EDM operation. The workpiece material is fixed on the machine table while the wire electrode moves according to a programmed path producing the contour of the work piece. In modern $\mathrm{CNC}$ WEDM machines five axes can be programmed to be simultaneously moved (X, Y, U, V, Z). The contour of the workpiece is normally produced by one main or rough cut, followed by a sequence of two or more trim cuts. The trim cuts are employed in order to approach or reach the final accuracy and surface quality of the workpiece.

In this work, the above process parameters were varied to analyze their influences on the wire feed rate $V_{f}[\mathrm{~mm} /$ min]. For each one of the parameter settings three tests were executed using a constant discharge current $i_{e}$ of 8 [A] and an open circuit voltage $u_{i}$ set at $80 \mathrm{~V}$, and no significant differences among them were observed. $20 \mathrm{~mm}$ long straight cuts, spaced of $2 \mathrm{~mm}$ from each other, were made into a $1 \mathrm{~mm}$ thick Ti6Al4V plate with the physical and mechanical properties shown in Table 1. De-ionized water $(15 \mu \mathrm{S} / \mathrm{cm})$ was used as dielectric fluid for all the experiments.

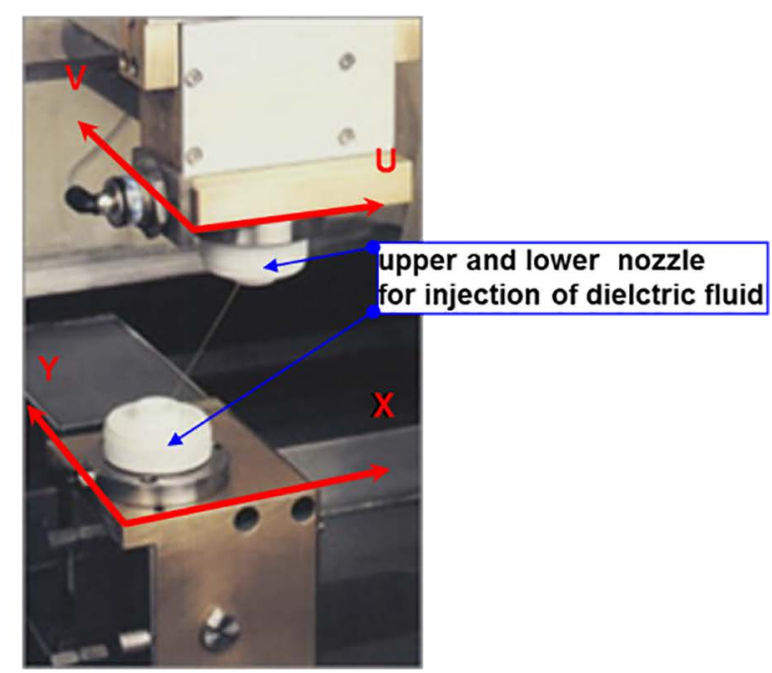

(B)

Figure 1. (A) schematic picture of a WEDM operation method and (B) WEDMachine used in this work depicting the nozzles to inject the de-ionized water dielectric 
Table 1. Physical and mechanical propertis of Ti6Al4V.

\begin{tabular}{lcc}
\hline Density & $\mathrm{g} / \mathrm{cm}^{3}$ & 4.42 \\
Melting point & ${ }^{\circ} \mathrm{C}$ & 1649 \\
Specific heat & $\mathrm{J} / \mathrm{Kg} .{ }^{\circ} \mathrm{C}$ & 560 \\
Electric resistivity & $\mathrm{Ohm} . \mathrm{cm}$ & 170 \\
Thermal conductivity & $\mathrm{W} / \mathrm{m} . \mathrm{K}$ & 7.2 \\
Yield strenght & $\mathrm{MPa}$ & $897-1000$ \\
Modulus of elasticity & $\mathrm{GPa}$ & 114 \\
Hardness & $\mathrm{HR}_{\mathrm{C}}$ & 36 \\
\hline
\end{tabular}

The wire pre-tensioning force $\mathrm{F}_{\mathrm{d}}=10 \mathrm{~N}$ was applied to the wire between the brake pulley and the feeding pulley to compensate the wire deflection caused by process forces.

Surface integrity of the Ti6Al4V alloy $1 \mathrm{~mm}$ thick plate samples were analyzed for the best obtained WEDMachining results. The samples were prepared with the aid of a sequence of $\mathrm{SiC}$ sandpaper and subsequently polished with diamond paste. Kroll reagent was used to improve the contrast of the samples attacked. The surface of the samples was analyzed by a scanning electron microscope (SEM) model VEGA3, manufactured by TESCAN.

\section{Results and Discussions}

The major objective of a WEDMachining main cut is to promote high material removal rate $[\mathrm{mm} 2 / \mathrm{min}]$ or high wire feed rate $V_{f}[\mathrm{~mm} / \mathrm{min}]$ with the wire eroding through its full diameter. According to Prohaszka et. al. ${ }^{11}$ the ideal wire electrode must have three important characteristics: high electrical conductivity, sufficient mechanical strength and to be able to promote optimum spark formation and flushing conditions. Nevertheless, the electrical variables are also very important for WEDM performance. Figure 2 presents the influence of interval time $t_{o}$ on the wire feed rate $V_{f^{\prime}}$

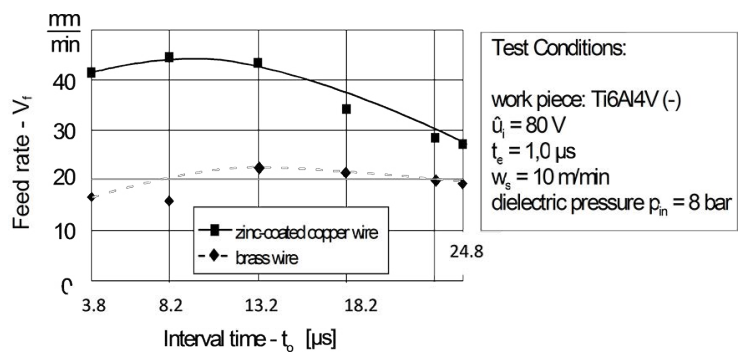

Figure 2. Influence of the variation of interval time $t_{0}$ on wire feed rate $\mathrm{V}_{\mathrm{f}}$ for brass and zinc-coated copper wires

For the copper wire with a diffused zinc coating it can be seen a considerable increase of $V_{f}$ when the interval time $t_{0}$ is reduced from $24.8 \mu$ s to $8.2 \mu$ s, which represents the best value of $t_{0}$. The reduction of $t_{0}$ promoted higher values of $V_{f}$ because the pulse cycle period $\left(t_{p}=t_{e}+t_{o}\right)$ was reduced, therefore increasing the discharge frequencies $\left(\mathrm{f}=1 / \mathrm{t}_{\mathrm{p}}\right)$ while adequate WEDM stability was maintained, i.e., few occurrence of short-circuits and arc-discharges. The maximum feed rate of about $V_{f}=44 \mathrm{~mm} /$ min was reached for coated copper wire.

When WEDM with uncoated brass wire a similar behavior can be noticed, but the intensity of the influence of $t_{o}$ in $V_{f}$ is not the same as that of zinc-coated copper wire. For brass wire the best interval time $\left(\mathrm{t}_{\mathrm{o}}=13.2 \mu \mathrm{s}\right)$ promoted $23 \mathrm{~mm} /$ min of feed rate value, much lower than that of zinc-coated copper wire.

Prohaszka et. al. ${ }^{11}$ point out that the first commercial wire electrodes were made of uncoated copper because the experience on die-sinking EDM. However, copper wears very rapidly under the WEDM electro-thermal conditions and its tension capability is rather poor, resulting in machining instabilities due to a high degree of short-circuits and arcdischarges. Copper also has inconveniences such as high melting point and low vapor pressure rating that contribute to lower the performance of WEDM operations. Later in the early 70 's the development of brass alloy wires $(63 \% \mathrm{Cu}$, $37 \% \mathrm{Zn}$ ) with higher tensile strength improved the cutting speed. The addition of zinc also provided a lower melting point and a higher vapor pressure rating to the wire, resulting in cutting speed better than those of uncoated copper wires. However, brass alloy cannot be manufactured with higher values of zinc.

As reported by Convers \& Balley ${ }^{12}$ in order to avoid the shortcomings of the aforementioned wires and to rather increase speed and accuracy, coated wire electrodes were introduced in the WEDM market. These wires are normally composed of a brass or copper core that is coated with zinc or $\mathrm{ZnO}$ layer of 20 to $30 \mu \mathrm{m}$ thickness. The coating layer has a much higher vapor pressure rating and a melting point lower than the wire core material. So, when the pulse voltage is applied across the working gap the wire coating is overheated and then evaporated. This phenomenon makes the ionization channel to be faster created. The working gap size also increases, promoting better flushing conditions. The end results are higher cutting speeds and cutting precision when WEDM with coated wires, as shown in Fig.2. The above discussion explains the extra improvement performance of zinc-coated copper wire in comparison to uncoated brass wire used in experiments of this work (Fig. 2 to Fig. 5).

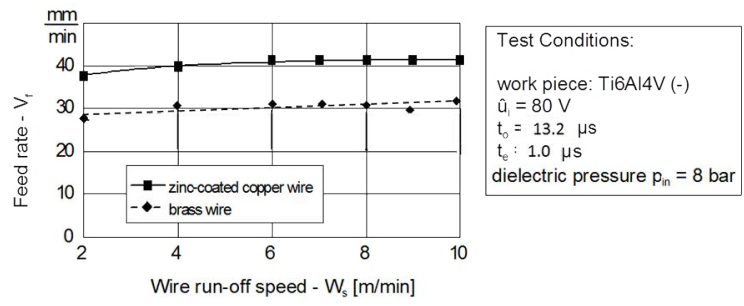

Figure 3. The influence of wire run-off speed $W_{s}$ on the wire feed rate $\mathrm{V}_{\mathrm{f}}$ for uncoated brass and zinc-coated copper wires 
(A) New coated copper wire

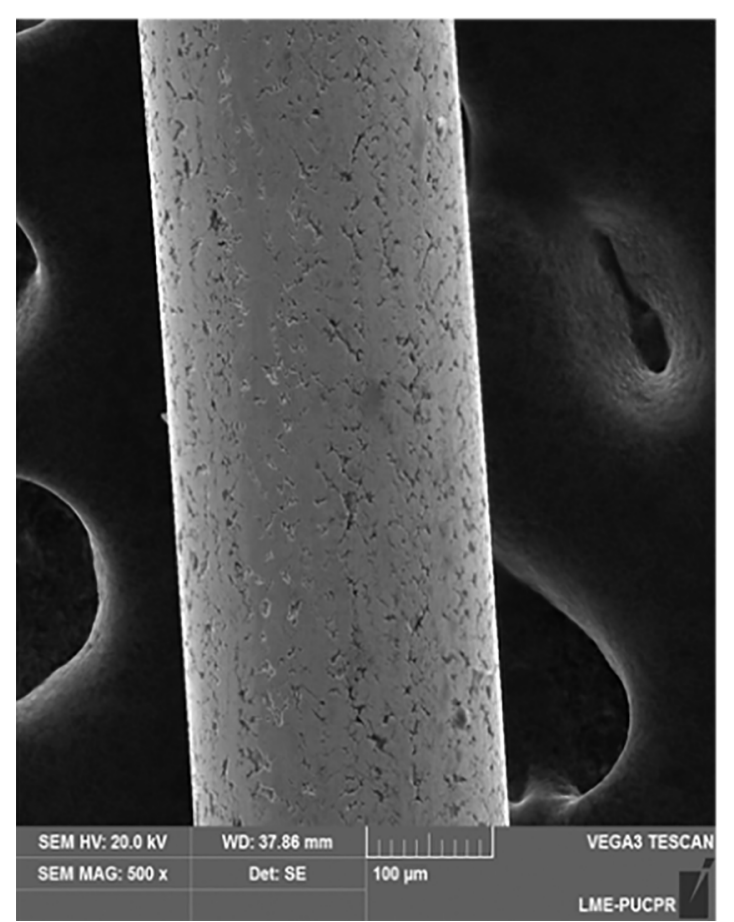

(B) Worn coated copper wire

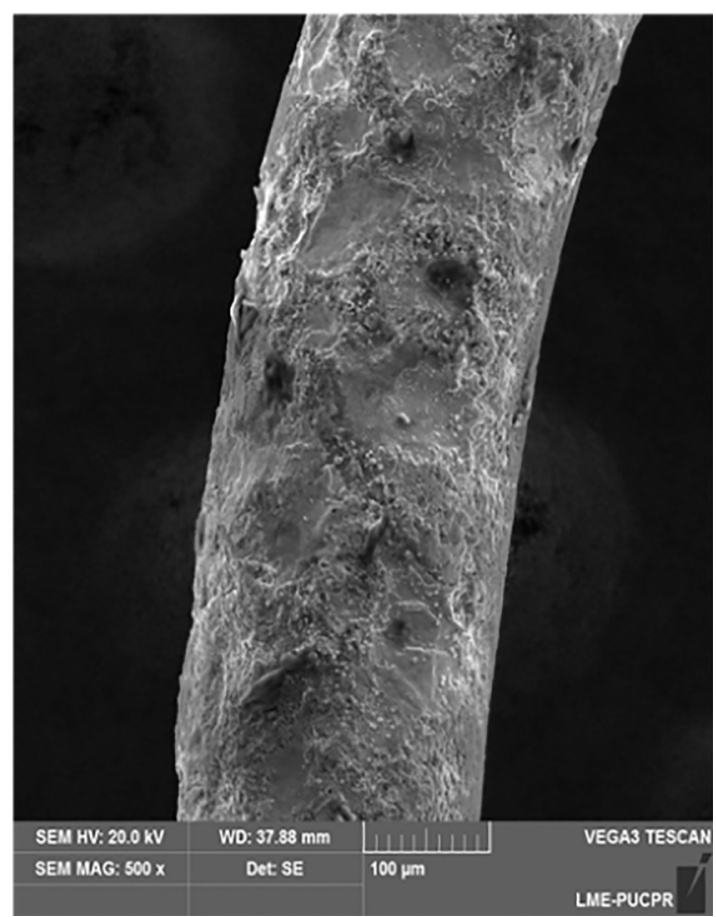

Figure 4. SEM images of (A) new and (B) worn copper wire with a diffused zinc coating when using $\mathrm{W}_{\mathrm{s}}=2 \mathrm{~m} / \mathrm{min}$

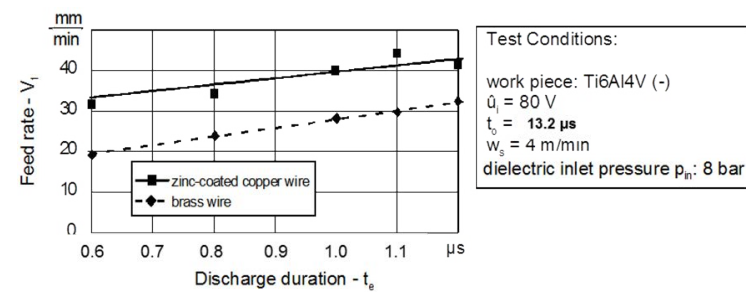

Figure 5. The influence of discharge duration $t_{e}$ on the wire feed rate $\mathrm{V}_{\mathrm{f}}$ for brass and zinc-coated copper wires

Figure 3 shows the influence of wire run-off speed $\mathrm{W}_{\mathrm{s}}$ on the results of wire feed rate $\mathrm{V}_{\mathrm{f}}[\mathrm{mm} / \mathrm{min}]$. In general, for both wire electrodes is clearly seen that $\mathrm{W}_{\mathrm{s}}$ (varying from 4 to $10 \mathrm{~mm} / \mathrm{min}$ ) presents just a few influence on the $\mathrm{V}_{\mathrm{f}}$ values. In order to reduce the consumption of wire and to keep a stable machining it is recommended to set $\mathrm{W}_{\mathrm{s}}=4$ $\mathrm{m} / \mathrm{min}$ when WEDM thin plates of Ti6A14V.

Figure 4 shows SEM images of a new and a worn copper wire with a diffused zinc coating when WEDM with $\mathrm{W}_{\mathrm{s}}=$ $2 \mathrm{~m} / \mathrm{min}$. When the wire run-off speed $\mathrm{W}_{\mathrm{s}}$ decreases from $10 \mathrm{~m} / \mathrm{min}$ to $2 \mathrm{~m} / \mathrm{min}$, the probability of a larger number of sparks occurring at one point of the wire increases. This, in turn, promotes a reduction of the radial area of the wire, which causes the wire to breakage, as the tension applied to the wire increases.

The discharge energy $\left(\mathrm{W}_{\mathrm{e}}=\mathrm{u}_{\mathrm{e}} \cdot \mathrm{i}_{\mathrm{e}} \cdot \mathrm{t}_{\mathrm{e}}[\mathrm{J}]\right)$ supplied in the working gap has significant influence on the wire feed rate $\mathrm{V}_{\mathrm{f}}[\mathrm{mm} / \mathrm{min}]$ through the contour of the workpiece material.
The higher the value of the $\mathrm{W}_{\mathrm{e}}$ the higher the value of $\mathrm{V}_{\mathrm{f}}$. Figure 5 presents the results of the variation of discharge duration $\mathrm{t}_{\mathrm{e}}$ against the results of $\mathrm{V}_{\mathrm{f}}$. For both wires the increase of $t_{e}$ promoted enhanced WEDM performance. Higher values of $t_{e}$ means that more material will be molten and evaporated in the workpiece, yielding better material removal at the end of the pulse. The better results for coated copper wire in relation to uncoated brass wire were already explained previously. The optimum discharge duration $t_{e}$ for both wires is $1.1 \mu \mathrm{s}$ which promoted the best wire feed rate. Raising the value of $\mathrm{t}_{\mathrm{e}}$ beyond $1.1 \mu$ s would probably cause the wire breakage because positive ions from the workpiece would erode the wire excessively.

The de-ionized water dielectric fluid is responsible for concentrating the plasma channel energy, cooling the wire and workpiece and flushing the eroded particles away from the working gap. Figure 6 shows the influence of the dielectric inlet pressure $\mathrm{P}_{\text {in }}$ on the wire feed rate. Tests were carried out from no-pressure flushing to 8 bar pressure flushing $\mathrm{P}_{\text {in }}$. With no-pressure flushing the feed rate is quite slow because the eroded particles are not properly expulsed from the gap. It has occasionally caused wire breakage and in many times short-circuits, decreasing the $\mathrm{V}_{\mathrm{f}}$ values. On the other hand, the use of high pressure flushing ( 8 bar) is not recommended because deflection of the thin plate can occurs. It is recommended 3.5 bar dielectric inlet pressure $\mathrm{P}_{\text {in }}$, so that providing stable WEDMachining with no arcs or short-circuits, as well as no wire excessive vibration. 


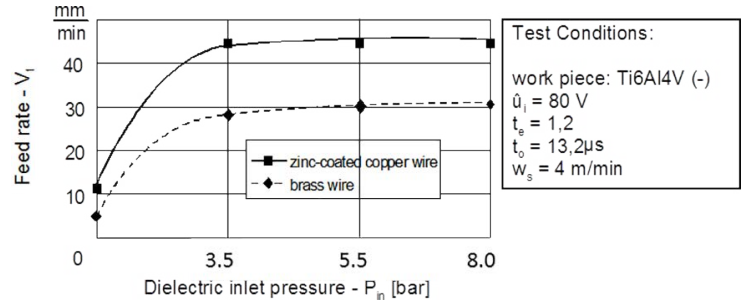

Figure 6. The influence of dielectric inlet pressure $P_{\text {in }}$ on the wire feed rate $\mathrm{V}_{\mathrm{f}}$ for uncoated brass and zinc-coated copper wires

According to VDI standard $3402{ }^{13}$ different layers can be identified in workpieces after EDM, which are briefly described as follows:

(a) Recast layer - the surface layer of the electroeroded parts. It is formed by the molten material during the discharge that is not expelled away by flushing, when the plasma channel collapses, and then solidifies again on the surface. Usually contains inclusions or byproducts resulting from the reaction with the dielectric, in addition to pores, cracks and residual stresses.

(b) Phase transformation zone - It is located just below the recast layer and was not melted during the discharge. This zone is usually composed of several layers that are difficult to be distinguished. It presents microstructural and chemical composition modification due to high temperatures and by migration of atoms from places with high concentration to places with lower concentration. Depending on the material of the part the phase transformation zone may present residual stresses, pores and cracks.

(c) Conversion zone - located below the transformation zone where changes in the microstructure of the material can be noticed in relation to be base material.

(d) Residual stress zone - a zone in which the high temperature gradient, promoted by the heating and cooling cycle of the material during the electroerosion, causes the formation of residual stresses from the surface layer to areas close to the base material of the alloy.

The titanium alloy Ti6A14V is a material containing $6 \%$ in weight of aluminum and $4 \%$ in weight of vanadium. This alloy in slow cooling conditions has two phases. The $\alpha$ phase, which has a dark gray appearance and $\beta$ phase, which has a light gray appearance, as shown in Figs. 7 and 8 . The $\alpha$ phase is the matrix and the $\beta$ phase is the precipitate.

Figures 7A and 7B show the cross-sectional aspect of the annealed zone of titanium alloy Ti6A14V machined by the WEDM process with the uncoated brass wire, using interval time $t_{0}$ of 13.2 and $23.2 \mu$ s, respectively. The two values of $t_{o}$ seem to influence the thickness of the recast layer, in the case of the samples examined. The interval time $t_{o}$ of 23.2 $\mu$ s indicates the presence of a recast layer more uneven and with a slightly more porous aspect. In both figures the presence of thermal cracks is observed. Also, the presence of particles that have been released from the body of the sample during the procedure of metallographic preparation is seen.
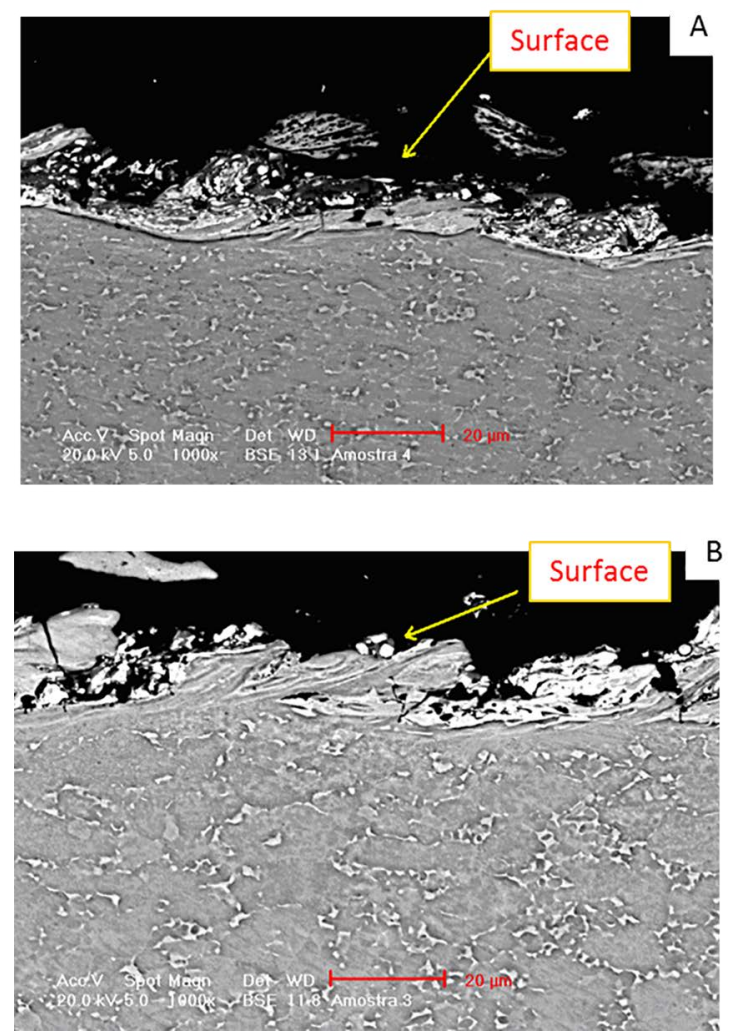

Figure 7. Aspect of the recast layer of the Ti6Al4V alloy machined by the WEDM process with a brass wire, using interval time $t_{0}$ of (A) $13.2 \mu \mathrm{s}$ and (B) $23.2 \mu \mathrm{s}$

Figures $8 \mathrm{~A}$ and $8 \mathrm{~B}$ show the aspect of the recast layer of the Ti6Al4V alloy from the WEDM process using zinc-coated copper wire for interval times $t_{0}$ of 13.2 and $23.2 \mu \mathrm{s}$, respectively. The thickness of the recast layer is lower compared to the case previously seen when a brass wire was used. It is also noted that the interval time $t_{o}$ has little influence on the aspect of the recast layer when the zinc-coated copper wire is used. The recast layer is compact in appearance and without the presence of pores, in the case of machining with the use of zinc-coated copper wire. The recast layer presents thermal cracks arising from the heating and cooling process. For the case of using the interval time of $13.2 \mu \mathrm{s}$, the presence of particles - upper left corner of Figure 8A - is verified, suggesting that this layer, being smaller than that machined with uncoated brass wire, can be easily removed by a polishing process performed after the WEDM process. 

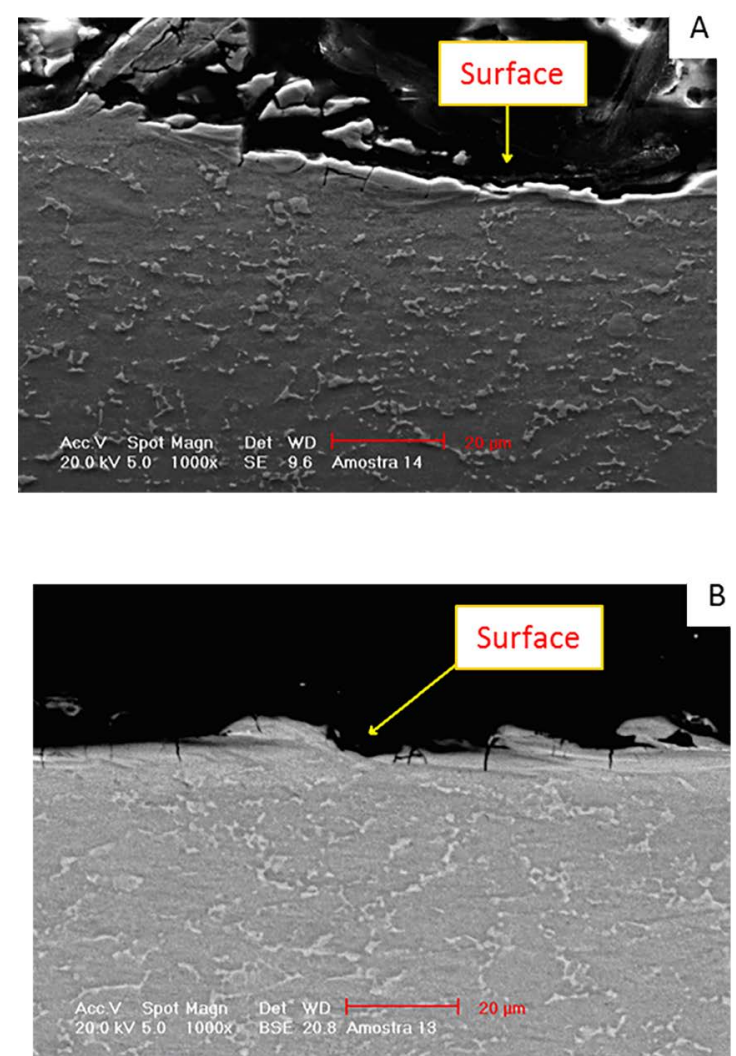

Figure 8. Aspect of the recast layer of the Ti6Al4V alloy machined by the WEDM process with a zinc-coated copper wire, using interval time $\mathrm{t}_{\mathrm{o}}$ of (A) $13.2 \mu \mathrm{s}$ and (B) $23.2 \mu \mathrm{s}$

\section{Conclusions}

In this work the influences of uncoated brass wire and copper wire with a diffused zinc coating and electrical variables when WEDM a thin plate of Ti6Al4V alloy were investigated. Surface integrity characteristics of Ti6Al4V workpiece samples were also analyzed. It can be concluded that the zinc-coated copper wire promoted the best results on the wire feed rate $V_{f}$ due to zinc coating higher vapor pressure rating and a melting point lower than the wire core material making the ionization channel to be faster created; the wire run-off speed $\mathrm{W}_{\mathrm{s}}$ has just little influence on $\mathrm{V}_{\mathrm{f}}$ when WEDM thin plate of Ti6Al4V; the increase of discharge duration $t_{e}$ up to $1.1 \mu$ s increases the wire feed rate $\mathrm{V}_{\mathrm{f}}$; the optimum interval time $t_{\mathrm{o}}=13.2 \mu$ s provided the highest wire feed rate $\mathrm{V}_{\mathrm{f}}$ for both wire electrodes and the dielectric inlet pressure $\mathrm{P}_{\mathrm{in}}=3.5 \mathrm{bar}$ is recommended for good flushing conditions. The surface integrity of the Ti6Al4V alloy is influenced by the type of wire used in the WEDM process. In this case, the recast layer of the samples machined with zinc-coated copper wire presented smaller thickness and more compact than that obtained in the WEDM with uncoated brass wire. For machining with both types of wires, the existence of thermal cracks was observed.

\section{References}

1. Gu L, Lei L, Zhao W, Rajurkar KP. Electrical discharge machining of Ti6Al4V with a bundled electrode. International Journal of Machine Tools \& Manufacture. 2012;53(1):100-106.

2. Zhao W, Wang Z, Di S, Chi G, Wei H. Ultrasonic and electric discharge machining to deep and small hole on titanium alloy. Journal of Materials Processing Technologies. 2002;120(13):101-106.

3. Znidarsic M, Junkar M. Deep Small Hole Drilling with EDM. In: Proceedings of 4th International Conference on Advanced Manufacturing Systems and Technology; 1996 Sep; Udine, Italy.

4. Ezugwu EO, Bonney J, Yamane Y. An overview of the machinability of aeroengine alloys. Journal of Materials Processing Technology. 2003;134(2):233-253.

5. Ho KH, Newman ST. State of the art electrical discharge machining (EDM). International Journal of Machine Tools and Manufacture. 2003;43(13):1287-1300.

6. Masuzawa T. State of the Art of Micromachining. Annals of CIRP. 2000;49(2):473-488

7. Masuzawa T. An Approach to Micromachining through Machine Tool Technology. In: Proceedings of 2nd International Symposium on Micro Machine and Human Sciences; 1991; Nagoya, Japan. p. 47-52.

8. Abbas NM, Solomon DG, Bahari MF. A review on current research trends in electrical discharge machining (EDM). International Journal of Machine Tools and Manufacture. 2007;47(7-8):1214-1228.

9. Hasçalik A, Çaydas U. Electrical discharge machining of titanium alloy (Ti-6Al-4V). Applied Surface Science. 2007;253(22):90079016.

10. Klocke F, Lung D, Thomaidis D, Antonoglou G. Using ultra thin electrodes to produce micro-parts with wire-EDM. Journal of Materials Processing Technologies. 2004;149(1-3):579-584.

11. Prohaszka J, Mamalis AG, Vaxevanidis NM. The effect of electrode material on machinability in wire electro-discharge machining. Journal of Materials Processing Technologies. 1997;69(1-3):233-237.

12. Convers D, Balley J, inventors. Electrode for Electrical Discharge Machining. United States patent US 4341 939. 1981.

13. VDI - Verein Deutscher Ingenieur. VDI 3402 - Elektroerosive Bearbeitung: Definitionen und Terminologie. Düsseldorf: VDI; 1990. 